\title{
Pengoprasionalan Cultivaltor di Kampung Kobrey Distrik Ransiki dalam Peningkatan Kompetensi Petani
}

\author{
Latarus Fangohoi ${ }^{1 *}$, Immanuel Womsiwor ${ }^{1}$, Egidius Gaspar Kara ${ }^{1}$ \\ ${ }^{1}$ Program Studi Penyuluhan Pertanian Berkelanjutan, Politeknik Pembangunan Pertanian \\ Manokwari \\ *Corresponding author: latarus@polbangtanmanokwari.ac.id
}

\begin{abstract}
Abstrak
Cultivator adalah alat dan mesin pertanian yang digunakan untuk pengolahan tanah sekunder dimana sebelumnya tanah sudah diolah. Penelitian ini bertujuan untuk mengetahui kompetensi petani dalam pengoperasian cultivator dan mengetahui faktor-faktor karakteristik petani (tingkat pendidikan, umur dan lama berusahatani) yang mempengaruhi kompetensi petani dalam mengoperasionalkan cultivator. Metode penelitian yang digunakan adalah jenis data primer dan sekunder yang bersifat kualitatif dan kuantitatif. Variabel yang diamati yaitu kompetensi petani dalam pengoperasian cultivator dengan parameter yang diukur yaitu pengetahuan dan keterampilan. Kegiatan penyuluhan pada kelompok tani Mamantoa di Kampung Kobrey cukup efektif meningkatkan pengetahuan petani hasil ini dapat terlihat dari nilai rata-rata persentase efektifitas penyuluhan sebesar 47,76 point masuk dalam kriteria cukup efektif., namun petani kurang terampil dalam mengoperasionalkan cultivator, sehingga petani berada pada kriteria kompetensi cukup dalam memahami dan mengeoperasikan cultivator, yaitu sebanyak 17 orang, dan sisanya sebanyak 3 orang memiliki kompetensi baik.
\end{abstract}

Kata kunci: Cultivator, Kompentensi petani, Penyuluhan

\section{Abstract}

Cultivator is a tool and agricultural machine used for the processing of secondary soil where previously the land was already in the sport. This research aims to determine the competence of farmers in the operation of Cultivator and know the characteristics factors of farmers (education level, age and long-farming) that affects the competence of farmers in operationalize cultivator. The research methods used are the primary and secondary data types that are qualitative and quantitative. The observed variable is the competency of farmers in the operation of cultivator with measured parameters of knowledge and skills. Extension activities at the Mamantoa Farmer group in Kampung Kobrey are effective enough to increase the knowledge of farmers this result can be seen from the average value of the effectiveness of the counseling of 47.76 points entered in the criteria quite effective., but farmers are less skilled in operationalize Cultivator, so farmers are on the criteria of competency enough in understanding and operating Cultivator, which is 17 people, and the remaining 3 people have the competence of good.

Keywords: Cultivator, Extension, Farmer competence 
Prosiding Seminar Nasional Pembangunan dan Pendidikan Vokasi Pertanian

Politeknik Pembangunan Pertanian Manokwari, 31 Juli 2021

e ISSN : 2774-1982

DOI :

\section{PENDAHULUAN}

Menurut Riyansah (2008) alat dapat didefinisikan sebagai perkakas sederhana yang berguna meringankan dan mempermudah pekerjaan sehingga dapat mengurangi tenaga manusia. Sedangkan mesin diartikan sebagai suatu alat yang digerakkan secara mekanis, yang disertai dengan adanya perubahan dari satu bentuk energi ke dalam bentuk energi lainnya (Pratomo, 1983). Cultivator adalah alat dan mesin pertanian yang digunakan untuk pengolahan tanah sekunder dimana sebelumnya tanah sudah diolah. Program Kemitraan Masyarakat menghasilkan petani yang terampil menggunakan traktor cultivator mini untuk mengolah lahan pertanian mereka. Dengan pemanfaatan peralatan modern akan mempersingkat waktu pengolahan lahan dan menghemat tenaga petani.

Ada lima jenis karakteristik kompetensi menurut Palan (2008), yaitu: a) Pengetahuan (knowledge) merujuk pada informasi dan hasil pembelajaran. b) Keahlian (skill) merujuk pada kemampuan melakukan suatu kegiatan. c) Konsep diri (selfconcept) dan nilai-nilai (values) konsep diri dan nilai-nilai merujuk pada sikap, nilai-nilai dan citra diri seseorang. d) Karakteristik pribadi (traits) Karakteristik pribadi merujuk pada karakteristik fisik dan konsistensi tanggapan terhadap situasi atau informasi. e) Motif (motives) merupakan emosi, hasrat, kebutuhan psikologis, atau dorongan-dorongan lain yang memicu tindakan. Keberhasilan petani dalam berusahatani erat kaitannya dengan kompetensi agribisnis yang dimiliki petani dalam mengelola usaha taninya.

Kompetensi agribisnis adalah kemampuan petani untuk berpikir, bersikap dan bertindak dalam merencanakan usahatani untuk memperoleh keuntungan berusahatani, membangun kerjasama antar subsistem pertanian, mengelola pasca panen pangan untuk meraih nilai tambah produk pertanian, serta mewujudkan kegiatan pertanian yang berkelanjutan (Harijati, 2007). Menurut Rogers (1983), tiga jenis pengetahuan (knowledge) sebagai berikut: 1) Pengetahuan akan keberadaan inovasi (Awarenessknowledge); 2) Pengetahuan tentang cara menggunakan inovasi (How-to-knowledge); 3) pengetahuan tentang prinsip-prinsip mendasari bagaimana dan mengapa inovasi dapat bekerja (Principles-knowledge). Pengetahuan dapat diperoleh dengan melakukan pencarian informasi di berbagai media informasi elektronik berupa internet dalam menambah skill (Fangohoi et al., 2018). 
Prosiding Seminar Nasional Pembangunan dan Pendidikan Vokasi Pertanian

Politeknik Pembangunan Pertanian Manokwari, 31 Juli 2021

e ISSN : 2774-1982

DOI : https://doi.org/10.47687/snppvp.v2i1.196

\section{METODE}

Penelitian ini mengunakan jenis data yang terdiri dari data primer dan sekunder yang bersifat kualitatif dan kuantitatif dengan metode pengambilan data yaitu observasi, wawancara, kuesinoer dan dokumentasi. Variabel yang diamati yaitu kompetensi petani dari tingkat pendidikan, umur dan lama berusahatani dalam pengoperasian cultivator dengan parameter yang diukur pengetahuan (knowledge) dan keterampilan (skill).

\section{HASIL DAN PEMBAHASAN}

\section{Kompetensi Pengetahuan dan Keterampilan}

Pengolahan lahan masih dilakukan dengan menggunakan peralatan pertanian yang sederhana, belum menggunakan tenaga penggerak, sehingga memerlukan tenaga yang besar dan waktu yang lama dalam penggarapan tanah. Berdasarkan hal tersebut perlu adanya teknologi tepat guna yang dapat digunakan untuk membantu petani. Mesin cultivator merupakan mesin yang dapat digunakan untuk mengatasi permasalahan yang dihadapi petani.

Kapasitas kerja suatu alat pengolahan tanah dipengaruhi oleh berberapa faktor, yaitu: 1) Ukuran dan bentuk petakan; 2) Topografi wilayah; 3) Keadaan traktor; 4) Keadaan vegetasi di permukaan tanah; 5) Keadaan tanah; 6) Tingkat keterampilan operator; dan 7) Pola pengolahan tanah.

Kompetensi pengetahuan yaitu pengetahuan yang dimiliki responden tentang Cultivator dan pengoperasiannya. Pengetahuan dipengaruhi akan tingkat Pendidikan dalam memperoleh informasi (Fangohoi et al., 2017). Kompetensi pengetahuan diukur dari tes akhir (post-test). Sedangkan kompetensi keterampilan yaitu keterampilan yang dimiliki responden dalam pengoperasian cultivator, yang diukur dari keterampilan per individu dalam mengoperasikan cultivator.

Tabel 1. Kompetensi Responden Berdasarkan Tes Pengetahuan dan Tes Keterampilan pada Kelompok Tani Mamantoa di Kampung Kobrey

\begin{tabular}{cccc}
\hline No. & Kompetensi & $\begin{array}{c}\text { Jumlah } \\
\text { (Jiwa) }\end{array}$ & $\begin{array}{c}\text { Persentase } \\
(\boldsymbol{\%})\end{array}$ \\
\hline 1. & Baik $(>40-60)$ & 3 & - \\
2. & Cukup $(>20-40)$ & 17 & - \\
3. & Kurang $(0-20)$ & - & - \\
\hline & Jumlah & $\mathbf{2 0 , 0 0}$ & - \\
\hline
\end{tabular}


Prosiding Seminar Nasional Pembangunan dan Pendidikan Vokasi Pertanian

Politeknik Pembangunan Pertanian Manokwari, 31 Juli 2021

e ISSN : 2774-1982

DOI : https://doi.org/10.47687/snppvp.v2i1.196

Responden dominan memiliki kompetensi cukup (cukup berkompetensi) dalam memahami dan mengeoperasikan cultivator, yaitu sebanyak 17 orang, dan sisanya sebanyak 3 orang memiliki kompetensi baik.

\section{Faktor-Faktor yang Mempengaruhi Kompetensi Petani}

Faktor-faktor yang mempengaruhi kompetensi petani dalam memahami dan mengoperasikan cultivator dalam kajian ini dianalisis pada uji pengetahuan dan uji keterampilan berdasarkan karakteristik petani (umur, tingkat pendidikan, dan lama bertani).

Umur

Kompetensi responden berdasarkan strata umur disajikan pada Tabel 2.

Tabel 2. Kompetensi Responden Berdasarkan Umur pada Kelompok Tani Mamantoa di Kampung Kobrey

\begin{tabular}{|c|c|c|c|c|c|c|}
\hline \multirow{2}{*}{$\begin{array}{c}\text { Strata } \\
\text { Umur } \\
\text { (tahun) }\end{array}$} & \multicolumn{2}{|c|}{ Tes Pengetahuan } & \multicolumn{2}{|c|}{ Tes Keterampilan } & \multicolumn{2}{|c|}{ Kompetensi } \\
\hline & $\begin{array}{c}\text { Nilai } \\
\text { Rataan }\end{array}$ & Kategori & $\begin{array}{c}\text { Nilai } \\
\text { Rataan }\end{array}$ & Kategori & $\begin{array}{c}\text { Nilai } \\
\text { Rataan }\end{array}$ & Kategori \\
\hline $\begin{array}{c}15-<37 \\
(11 \\
\text { orang) }\end{array}$ & $\begin{array}{c}24,18 \\
(48,73 \%)\end{array}$ & $\mathrm{CM}$ & $\begin{array}{c}7,73 \\
(51,69 \%)\end{array}$ & KT & $\begin{array}{c}31,91 \\
(49,41 \%)\end{array}$ & Cukup \\
\hline $\begin{array}{l}\geq 37-59 \\
(9 \text { orang) }\end{array}$ & $\begin{array}{c}25,44 \\
(51,27 \%)\end{array}$ & M & $\begin{array}{c}7,22 \\
(48,31 \%)\end{array}$ & KT & $\begin{array}{c}32,67 \\
(50,59 \%)\end{array}$ & Cukup \\
\hline
\end{tabular}

Umur responden seluruhnya berada pada usia produktif (15 - 59 tahun), dengan demikian digunakan analisis pada usia produktif, yaitu dengan cara membuat dua strata atau tingkatan yaitu umur $15-<37$ tahun dan $\geq 37-59$ tahun. Kompetensi responden berdasarkan umur pada Kelompok Tani Manantoa menunjukkan bahwa tidak ada perbedaan strata umur dengan kompetensi yang dimiliki, yaitu responden yang berumur $15-<37$ tahun dan $\geq 37$ - 59 tahun sama-sama memiliki kompetensi Cukup, artinya responden cukup memiliki kompetensi dalam memahami dan mengoperasikan cultivator. Dengan demikian dapat disimpulkan bahwa faktor umur tidak berpengaruh terhadap kompetensi responden dalam memahami dan mengoperasikan cultivator.

\section{Tingkat Pendidikan}

Tingkat pendidikan responden dominan berada pada tingkat pendidikan SD dan SMP, masing-masing sebanyak 8 orang. Kompetensi responden berdasarkan tingkat pendidikan pada kelompok tani Mamantoa menunjukkan bahwa tidak ada perbedaan tingkat pendidikan dengan kompetensi yang dimiliki, yaitu baik yang berpendidikan SD, SMP dan SMA memiliki kompetensi cukup, artinya responden cukup memiliki 
Prosiding Seminar Nasional Pembangunan dan Pendidikan Vokasi Pertanian

Politeknik Pembangunan Pertanian Manokwari, 31 Juli 2021

e ISSN : 2774-1982

DOI : https://doi.org/10.47687/snppvp.v2i1.196

kompetensi dalam memahami dan mengoperasikan cultivator. Dengan demikian dapat disimpulkan bahwa faktor tingkat pendidikan tidak berpengaruh terhadap kompetensi responden dalam memahami dan mengoperasikan cultivator. Kompetensi responden berdasarkan tingkat pendidikan disajikan pada Tabel 3.

Tabel 3. Kompetensi Responden Berdasarkan Tingkat Pendidikan pada Kelompok Tani Mamantoa di Kampung Kobrey

\begin{tabular}{ccccccc}
\hline \multirow{2}{*}{$\begin{array}{c}\text { Tingkat } \\
\text { Pendidikan }\end{array}$} & \multicolumn{2}{c}{ Tes Pengetahuan } & \multicolumn{2}{c}{ Tes Keterampilan } & \multicolumn{2}{c}{ Kompetensi } \\
\cline { 2 - 7 } & $\begin{array}{c}\text { Nilai } \\
\text { Rataan }\end{array}$ & Kategori & $\begin{array}{c}\text { Nilai } \\
\text { Rataan }\end{array}$ & Kategori & $\begin{array}{c}\text { Nilai } \\
\text { Rataan }\end{array}$ & Kategori \\
\hline $\begin{array}{c}\text { SD } \\
\text { (8 orang) }\end{array}$ & $\begin{array}{c}25,38 \\
(34,58 \%)\end{array}$ & $\mathrm{M}$ & $\begin{array}{c}4,38 \\
(17,95 \%)\end{array}$ & KT & $\begin{array}{c}29,75 \\
(30,43 \%)\end{array}$ & Cukup \\
\hline $\begin{array}{c}\text { SMP } \\
(4 \text { orang) }\end{array}$ & $\begin{array}{c}23,00 \\
(31,35 \%)\end{array}$ & $\mathrm{CM}$ & $\begin{array}{c}11,25 \\
(46,15 \%)\end{array}$ & $\mathrm{CT}$ & $\begin{array}{c}34,25 \\
(35,04 \%)\end{array}$ & Cukup \\
\hline $\begin{array}{c}\text { SMA } \\
(8 \text { orang })\end{array}$ & $\begin{array}{c}25,00 \\
(34,07 \%)\end{array}$ & $\mathrm{CM}$ & $\begin{array}{c}8,75 \\
(35,90 \%)\end{array}$ & KT & $\begin{array}{c}33,75 \\
(34,53 \%)\end{array}$ & Cukup \\
\hline
\end{tabular}

\section{Lama Bertani}

Kompetensi responden berdasarkan lama bertani disajikan pada Tabel 4 .

Tabel 4. Kompetensi Responden Berdasarkan Lama Bertani pada Kelompok Tani Mamantoa di Kampung Kobrey

\begin{tabular}{|c|c|c|c|c|c|c|}
\hline \multirow{2}{*}{$\begin{array}{c}\text { Lama } \\
\text { Bertani } \\
\text { (Tahun) }\end{array}$} & \multicolumn{2}{|c|}{ Tes Pengetahuan } & \multicolumn{2}{|c|}{ Tes Keterampilan } & \multicolumn{2}{|c|}{ Kompetensi } \\
\hline & $\begin{array}{c}\text { Nilai } \\
\text { Rataan }\end{array}$ & Kategori & $\begin{array}{c}\text { Nilai } \\
\text { Rataan }\end{array}$ & Kategori & $\begin{array}{c}\text { Nilai } \\
\text { Rataan }\end{array}$ & Kategori \\
\hline $\begin{array}{c}5-10 \\
(4 \text { orang) }\end{array}$ & $\begin{array}{c}22,75 \\
(22,81 \%)\end{array}$ & $\mathrm{CM}$ & $\begin{array}{c}11,25 \\
(35,59 \%)\end{array}$ & $\mathrm{CT}$ & $\begin{array}{c}34,00 \\
(25,88 \%)\end{array}$ & Cukup \\
\hline $\begin{array}{c}11-15 \\
(7 \text { orang) }\end{array}$ & $\begin{array}{c}25,29 \\
(25,35 \%)\end{array}$ & M & $\begin{array}{c}6,43 \\
(20,34 \%)\end{array}$ & KT & $\begin{array}{c}31,71 \\
(24,14 \%)\end{array}$ & Cukup \\
\hline $\begin{array}{c}16-20 \\
(7 \text { orang) }\end{array}$ & $\begin{array}{c}24,71 \\
(24,78 \%)\end{array}$ & $\mathrm{CM}$ & $\begin{array}{c}6,43 \\
(20,34 \%)\end{array}$ & KT & $\begin{array}{c}31,14 \\
(23,71 \%)\end{array}$ & Cukup \\
\hline $\begin{array}{c}\geq 21 \\
(2 \text { orang) }\end{array}$ & $\begin{array}{c}27,00 \\
(27,07 \%)\end{array}$ & M & $\begin{array}{c}7,50 \\
(23,73 \%)\end{array}$ & KT & $\begin{array}{c}34,50 \\
(26,26 \%)\end{array}$ & Cukup \\
\hline
\end{tabular}

Lama bertani responden dominan berada pada waktu 11 - 15 tahun dan 16 - 20 tahun, masing-masing sebanyak 7 orang. Kompetensi responden berdasarkan lama bertani pada Kelompok Tani Manantoa menunjukkan bahwa tidak ada perbedaan lama bertani dengan kompetensi yang dimiliki, yaitu baik yang bertani 5 -10 tahun, $11-15$ tahun, 16 20 tahun, dan $\geq 21$ tahun sama-sama memiliki kompetensi cukup, artinya responden cukup memiliki kompetensi dalam memahami dan mengoperasikan cultivator. Dengan demikian dapat disimpulkan bahwa faktor lama bertani tidak berpengaruh terhadap kompetensi. 
Prosiding Seminar Nasional Pembangunan dan Pendidikan Vokasi Pertanian

Politeknik Pembangunan Pertanian Manokwari, 31 Juli 2021

e ISSN : 2774-1982

DOI : https://doi.org/10.47687/snppvp.v2i1.196

\section{KESIMPULAN}

Kegiatan penyuluhan pada Kelompok Tani Mamantoa di Kampung Kobrey cukup efektif meningkatkan pengetahuan petani. Hasil ini dapat terlihat dari nilai rata-rata persentase efektifitas penyuluhan sebesar 47,76 point $(47,76 \%)$ masuk dalam kriteria cukup efektif, namun petani kurang terampil dalam mengoperasionalkan cultivator, sehingga petani berada pada kriteria kompetensi cukup dalam memahami dan mengeoperasikan cultivator, yaitu sebanyak 17 orang $(85,00 \%)$, dan sisanya sebanyak 3 orang $(15,00 \%)$ memiliki kompetensi baik. Faktor umur, tingkat pendidikan, dan lama berusahatani tidak berpengaruh terhadap kompetensi petani dalam memahami dan mengoperasikan cultivator pada Kelompok Tani Mamantoa di Kampung Kobrey.

\section{DAFTAR PUSTAKA}

Djoyowasito, G. (2002). Pengaruh Kecepatan Maju Bajak terhadap beberapa Sifat Dinamik Tanah dalam Pengolahan Tanah. Tesis. Fakultas Teknologi Pertanian. Institut Pertanian Bogor, Bogor.

Fangohoi, L., Sugiyanto, S., Sukesi, K., \& Cahyono, E.D. (2018). Establish the Perception of Agricultural Extension Workers Through Cyber Extension As the Media Information. Journal of Socioeconomics and Development, 1(1), 32-37. https://doi.org/10.31328/jsed.v1i1.530

Fangohoi, L., Sugiyanto, Sukesi, K., \& Dwi, C.E. (2017). the Role of Cyber Extension As Media Information of Plantation Genetic Resources in the Insurance of Cocoa Results in South Manokwari Regency West Papua. International Journal of Research -GRANTHAALAYAH, 5(11), 343-350. https://doi.org/10.29121/granthaalayah.v5.i11.2017.2362

Harijati, S. (2007). Potensi dan Pengembangan Kompetensi Agribisnis Petani Berlahan Sempit: Kasus Petani Sayuran di Kota dan Pinggiran Jakarta dan Bandung. Repository IPB, Bogor.

Palan, R. (2008). Competency Management. Penerbit PPM. Jakarta.

Rogers, E.M. (1983). Diffusion of Innovations. The Free Press, London.

Sayuti, M.R. (2014). Perancangan Transmisi Traktor Tangan Mini Dengan Motor Penggerak 5,5 HP Untuk Tanah Kering. Skripsi. Jurusan Teknik Mesin, Universitas Muhammadiyah Malang, 2014.

Hardjosentono, W., M. Rachlan, E. Badra, I.W., \& Tarmana, R.D. (1985). Mesin-Mesin Pertanian. Bumi Aksara, Jakarta.

Hendriadi, A., Sulistiadji, K., \& Prabowo, A. (2002). Analisis sistem dalam pengembangan alsintan pengolahan berbagai jenis tanah. http://mekanisasi.litbang.deptan. go.id/abstrak/th-2000/alsinpengolahan_tanah.htm. [17 April 2013].

Institut Pertanian Bogor (2010). Alat dan mesin pengolah tanah. http://web.ipb.ac.id/ tepfteta/elearning/media/Teknik\%20Mesin\%20Buditenagatr 
Prosiding Seminar Nasional Pembangunan dan Pendidikan Vokasi Pertanian

Politeknik Pembangunan Pertanian Manokwari, 31 Juli 2021

e ISSN : 2774-1982

DOI : https://doi.org/10.47687/snppvp.v2i1.196

akto\%20Pertanian/ Alat\%20Pengolahan\%20tanah/index4april.html. [17 April 2013].

Pramuhadi, G. (2004). Studi Hubungan Antara Beban Mesin Traktor dan Efi siensi Pengolahan Tanah. Tesis. Program Studi Ilmu Keteknikan Pertanian. Institut Pertanian Bogor, Bogor.

Rachman, A. (2000). Penyiapan lahan. http://balitra.net/ berita/menu.php. [17 April $2013]$.

Rizaldi, T. (2006). Mesin Peralatan. Departemen Teknologi Pertanian Universitas Sumatera Utara, Medan. 